\title{
Saúde bucal e indicadores socioeconômicos de comunidades quilombolas rural e urbana do Estado do Rio Grande do Sul, Brasil
}

\author{
Oral Health and Socioeconomic Indicators in Rural and Urban \\ Maroon Communities In The State Of Rio Grande do Sul, Brazil
}

\author{
Márcia Cançado Figueiredol \\ Bruna Poletto Benvegnúll \\ Patrícia Perez Lopes da Silveirall' \\ Aline Maciel Silvaiv \\ Kátia Valença Correia Leandro da Silva
}

\begin{abstract}
RESUMO
Introdução: Para proporcionar ações efetivas na busca pela saúde bucal, o acesso à saúde deve ser singularizado, conformeas necessidades da população alvoe, isso deve ser planejado a partirdelevantamentos e estudos que evidenciem o perfil da comunidade e que sirvam de parâmetro para o planejamento de futuras ações. Objetivo: Descrever a condição de saúde bucal de duas comunidades quilombolas no estado do Rio Grande do Sul, uma rural e outra urbana, e correlacioná-la com o perfil socioeconômico e a quantidade de flúor encontrada na água de consumo. Método: Para tal foram realizadas avaliações odontológicas e o nível sócio econômico de $25 \%$ das famílias do quilombo, além de realizar a coleta da água de consumo para medição do nível de flúor da comunidade rural. Resultados: No quilombo Costa da Lagoa, $40 \%$ dos adultos jovens apresentavam lesões cariosas, e o edentulismo acometia 13,4\% dos adultos. Quanto à escolaridade, $80 \%$ possuem o primeiro grau incompleto. No quilombo dos Alpes, $5 \%$ dos adultos jovens apresentavam lesões cariosas, e $18 \%$ dos adultos apresentavam edentulismo. $60 \%$ da população desta comunidade possuía o primeiro grau incompleto. A comunidade dos Alpes consumia água fluoretada e a comunidade Costa da Lagoa, não consumia. Conclusões: As duas comunidades apresentaram um baixo nível socioeconômico, viviam abaixo da linha da pobreza. A comunidade quilombola rural apresentou um percentual maior de dentes cariados e perdas dentárias, o que sugere ser uma população desassistida pelos benefícios advindos da água de abastecimento público fluoretada e, de assistência odontológica preventiva, educativa e restauradora. Foram encontrados altos índices de placa visível, sangramento gengival, cárie e perdas dentárias nas duas comunidades.
\end{abstract}

Palavras-chave: Quilombo. Odontologia. Água. Flúor

\begin{abstract}
Introduction: To provide effective action in pursuit of oral health, access to health care should be singled out as the needs of the target population, and this should be planned from surveys and studies which show the profile of the community and serve as a benchmark for planning future actions. Objective: To describe the oral health status of two maroon communities in the state of Rio Grande do Sul, a rural and other urban, and correlate it with the socioeconomic profile and the amount of fluoride found in drinking water. Method: For this dental reviews and the socioeconomic level of $25 \%$ of households were made Quilombo, besides performing the collection of drinking water for measuring the fluoride level of the rural community. Results: In the Quilombo Costa da Lagoa, $40 \%$ of young adults had carious lesions, tooth loss and affects $13.4 \%$ of adults. Regarding education, $80 \%$ had incomplete first degree. Quilombo in the Alpes, $5 \%$ of young adults had carious lesions, and $18 \%$ of adults were edentulous. $60 \%$ of the population of this community has incomplete
\end{abstract}

\footnotetext{
'Universidade Federal do Rio Grande do Sul (UFRGS) - Porto Alegre/RS - Brasil "Universidade Federal do Rio Grande do Sul (UFRGS) - Porto Alegre/RS - Brasil "'Universidade Federal do Rio Grande do Sul (UFRGS) - Porto Alegre/RS - Brasil Iv Universidade Federal do Rio Grande do Sul (UFRGS) - Porto Alegre/RS - Brasil vUniversidade Federal do Rio Grande do Sul (UFRGS) - Porto Alegre/RS - Brasil
} 
first degree. The community used the Alpes for water consumption arising from DMAE; since the Costa da Lagoa community used water from the local pond not fluoridated. Conclusions: The two communities had a low socioeconomic status, living below the poverty line. The rural maroon community showed a higher percentage of decayed teeth and tooth loss, which suggests that this underserved population by benefits from the fluoridated public water supplies, and educational and preventive dental care. In both communities were found high levels of visible plaque, bleeding gums, decay and tooth loss.

Keywords: Quilombo. Odontology. Water. Fluoride

\section{INTRODUÇÃO}

As comunidades quilombolas em geral são fechadas, portanto pouco se conhece a respeito de suas características gerais: quem são, como estão e como vivem.

Com relação ao Rio Grande do Sul, sabese que o Estado foi um grande centro de escravos. Todo o processo de charques e carnes salgadas era produzido com trabalho escravo. Atualmente sabemos que no Estado há 35 quilombos, entre eles rurais e urbanos ${ }^{1}$.

A partir da organização comunitária, as comunidades remanescentes do Rio Grande do Sul exercem sua capacidade de argumentação política, com agentes do movimento negros em Instituições de Ensino superior, fazendo com que o Estado Brasileiro, representado por suas instituições, venha reconhecer oficialmente, através de ordenamentos jurídicos e administrativos a existência destas comunidades. Nos últimos dez anos a sociedade rio-grandense se inseriu no debate de forma mais intensa sobre o reconhecimento formal do movimento quilombola gaúcho².

Por outro lado, sabe-se da importância da fluoretação da água de abastecimento público, em termos de abrangência coletiva, como método mais efetivo para prevenção da cárie dentária. Além disso, apresenta os maiores níveis de equidade, adesão, custo-efetividade e segurança, representando uma das principais e mais importantes medidas de saúde pública. A fluoretação das redes de abastecimento de água é reconhecida mundialmente, pois os benefícios de redução da cárie superam os riscos da fluorose dental, considerada seu único efeito colateral ${ }^{3}$.
Sabe-se que a fluoretação das redes de abastecimento de água no Brasil tornouse uma obrigatoriedade através de Lei. No entanto, existem locais do país onde não é encontrada a concentração necessária de flúor nas águas, não há saneamento básico ou os poços artesianos podem apresentar flúor em excesso, como é o caso das comunidades que vivem em zona rural.

Diante deste contexto, objetivou-se descrever as condições de saúde bucal de duas comunidades quilombolas no estado do Rio Grande do Sul, uma rural e outra urbana e correlacioná-las com o perfil socioeconômico e a quantidade de flúor encontrada na água de consumo.

\section{REVISÃo dE LITERATURA}

O Sul do Brasil, antiga Província de São Pedro, contou com a presença do negro desde o início de sua ocupação pelos portugueses, entre o fim do século XVII e início do XVIII.

As diversas expedições que ocorreram no Sul, antes mesmo da região ser definitivamente incorporada aos domínios da colônia portuguesa, foram acompanhadas por escravos, como as dos Campos de Viamão e do Estreito, no início do século XVIII. As estâncias e vilas formadas no período se mantiveram às custas do trabalho escravo, empregado nas principais atividades econômicas ali praticadas como as charqueadas, as olarias e, inclusive, a pecuária, com a criação de gado vacum ${ }^{4}$.

No que diz respeito à população cativa sulina, levantamento realizado em 1780 indicava que ela representava $28 \%$ da população total da capitania. Já em 1814 , os cativos 
de origem africana constituíam $31 \%$ da população ${ }^{5}$. Entre os anos de 1874 e 1884, o Rio Grande do Sul era a sexta província com maior número absoluto de escravos ${ }^{6}$.

Quilombo é um movimento amplo e permanente que se caracteriza pelas seguintes dimensões: vivência de povos africanos que se recusavam à submissão, à exploração, à violência do sistema colonial e do escravismo; formas associativas que se criavam em florestas de difícil acesso, com defesa e organização socioeconômica e política própria; sustentação da continuidade africana através de genuínos grupos de resistência política e cultural ${ }^{7}$.

Os quilombos do Sul do país eram, em geral, constituídos por pequenos agrupamentos de escravos fugidos. Essa característica explica-se em parte pelo fato de os cativos do Sul possuírem fácil acesso a países vizinhos para onde fugiam. Além disso, a falta de acidentes geográficos na região dos pampas que pudessem esconder os fugitivos dificultava a formação de grandes aglomerados humano ${ }^{5}$. Em geral, tais quilombos possuíam entre 10 e 30 integrantes, composto em sua maioria por homens.

As principais regiões econômicas e geográficas do Sul do país assentadas no braço feitorizado contavam com a presença de quilombos em seus arredores, como o litoral. O continente, a oeste das grandes lagoas existentes no estado, e a Serra (apesar da colonização tardia) também foram abrigo de diversas manifestações de resistência negra ${ }^{5}$.

Outra singularidade dos quilombos sulinos diz respeito à sua localização. Existia uma grande quantidade de quilombos vivendo muito próximos aos centros urbanos, especialmente nas regiões de Porto Alegre, Rio Pardo e Rio Grande. Eram constituídos por cativos urbanos, acostumados ou conquistados pela vida citadina. A vida rural Ihes seria desconhecida ou pouco atraente ${ }^{5}$.

Hoje, no Brasil, estudos realizados por diferentes profissionais educadores, soció- logos, antropólogos, historiadores e juristas buscam determinados critérios para denominar a luta quilombola: comunidades negras rurais, terras de pretos, remanescentes de comunidades de quilombos, hoje Comunidades Remanescentes de Quilombos compreendendo: descendentes dos primeiros habitantes da terra; trabalhadores rurais que ali mantém sua residência habitual ou permaneçam emocionalmente vinculados ${ }^{8}$.

Os debates em torno destas designações ganham sentido, sobretudo, para efeito de medidas legais, jurídicas ou definição de direitos sociais, econômicos e políticos para os quilombolas e seus descendentes. Por exemplo, direito à legalização da terra, à moradia, à educação, à saúde e ao lazer.

As comunidades quilombolas rurais estão presentes em todo o Rio Grande do Sul. No entanto, em algumas regiões elas aparecem em maior concentração. É o caso do litoral e de toda a região localizada entre as lagoas e o oceano Atlântico que abarca municípios como os de São José do Norte, Tavares, Mostardas, Palmares do Sul, Capivari do Sul, Maquiné e Terra de Areia. Nessa região estão as comunidades de Casca, Limoeiro, Beco dos Coloidianos, Teixeiras, Olhos D'Água, Capororoca e Costa da Lagoa.

Não é mera coincidência que as regiões com grande concentração de comunidades quilombolas sejam justamente, as que contavam com maior número de população escrava no passado. A faixa litorânea do estado e a região do atual município de Porto Alegre e arredor foram as primeiras áreas ocupadas pelos portugueses, que levaram muitos escravos para o local. O arroio Pelotas, a oeste da laguna dos Patos, foi um importante centro de produção de charque, a atividade econômica que mais empregou mão-de-obra escrava no sul do país.

Ao se falar em quilombo, que na língua Banto significa "povoação", logo vem em mente 
o Quilombo dos Palmares, que realmente foi o mais conhecido do Brasil e é hoje o símbolo da luta do Movimento Negro. Sabe-se que este foi um núcleo de resistência formado por volta de 1600 na Serra da Barriga, em Alagoas; ao longo dos anos se fortificou, chegando a reunir quase 30 mil pessoas, que em aproximadamente 100 anos sofreram constantes ataques de holandeses e portugueses ${ }^{9}$.

Conta a história que Ganga Zumba foi o penúltimo rei deste quilombo, considerado o maior de que se tem notícia no país. Ele foi morto pelo sobrinho, Zumbi, que não aceitou o acordo feito pelo tio com os portugueses, em que prometia que os quilombolas não mais raptariam os negros ainda escravizados pelos fazendeiros. Zumbi liderou uma resistência heroica que findou com a destruição do quilombo e a sua própria morte, ocorrida em 20 de novembro de 1695. Devido ao significado desta luta, a data foi escolhida para marcar o "Dia Nacional da Consciência Negra"10.

Pode-se afirmar que cerca de $25 \%$ do Território Nacional Brasileiro é ocupado por povos e comunidades tradicionais, como indígenas, quilombolas, seringueiros e quebradeiras de coco babaçu, representando quase cinco milhões de pessoas. A questão primordial enfrentada por estes grupos é o acesso ao território, que faz parte da cosmologia do grupo, referendando um modo de vida e uma "Visão de Homem e de Mundo", além de assegurar a sobrevivência, uma vez que constituem a base para a produção e a reprodução dos saberes tradicionais ${ }^{11}$.

A Federação das Associações das Comunidades Quilombolas do Rio Grande do Sul informa que existem mais de 130 comunidades quilombolas em território gaúcho. O Cadastro Geral de Remanescentes de Comunidades de Quilombos do governo federal já registrava, em dezembro de 2007, a existência de 35 comunidades naquele estado.

Atualmente, é possível identificar algumas regiões com grande concentração de quilombos rurais no estado, tais como: o litoral rio-grandense-do-sul (municípios de São José do Norte, Mostardas, Tavares e Palmares do Sul); a região central (municípios de Restinga Seca, Formigueiro e entorno) e a Serra do Sudeste, a oeste da Lagoa dos Patos. A região metropolitana de Porto Alegre abriga pelo menos seis quilombos urbanos.

A principal luta dessas comunidades é, certamente, a garantia de suas terras. Em 2004, de acordo com o relato da líder da comunidade de Casca: "O nosso maior desafio é, tranquilamente, o título da terra. Porque a gente vem aguardando isso, esperando desde muito tempo". Apesar de se tratar de um direito assegurado pela Constituição Federal, até hoje apenas três terras de quilombo no Rio Grande do Sul foram tituladas. Uma importante conquista foi obtida em outubro de 2006, quando o Presidente da República assinou decreto declarando de interesse social a terra ocupada pela comunidade quilombola Família Silva, logo depois, assinou igual decreto para a terra do Quilombo Chácara das Rosas e autorizando o INCRA (Instituto Nacional de Colonização e Reforma Agrária) a proceder a desapropriação a fim de garantir os direitos territoriais das comunidades. Em 2009 quando os processos de desapropriação foram concluídos, as terras puderam ser tituladas em nome dos quilombos Família Silva e Chácara das Rosas. Em 2010, chegou a vez do Quilombo de Casca receber o título de apropriação de suas terras.

No entanto, muitas outras comunidades ainda aguardam por medidas efetivas para regularizar suas terras. Em janeiro de 2008, tramitavam pelo Instituto Nacional de Colonização e Reforma Agrária, órgão do governo federal responsável pela titulação das terras quilombolas, 33 processos de titulação, dos quais apenas cinco estavam em etapas mais avançadas, com o relatório de identificação do território concluído ${ }^{12}$. 
No trabalho de Santos e Santos ${ }^{13}$ há uma interessante revisão bibliográfica sobre a fluoretação das águas de abastecimento público no combate à cárie dentária. Segundo Ramires e Buzalaf ${ }^{3}$ a fluoretação das águas de abastecimento público, que consiste na adição controlada de um composto de flúor à água, é uma das mais importantes medidas de prevenção da cárie dentária na saúde coletiva.

No trabalho de Narvai ${ }^{14}$ encontramos alguns conceitos de Cury ${ }^{15}$ e Featherstone ${ }^{16}$. Ao longo da vida, ocorrem sucessivas desmineralizações e remineralizações do esmalte dentário, ocasionados pela queda de $\mathrm{pH}$ que a produção de ácidos gera. O flúor atua na prevenção da cárie formando fluoreto de cálcio na etapa de remineralização ${ }^{15}$. O fluoreto de cálcio torna o esmalte dentário menos solúvel em ácidos ${ }^{16} \mathrm{e}$, portanto, menos suscetível à desmineralização (processo que origina a cárie). Portanto, a presença contínua de pequenas quantidades de flúor no meio bucal ao longo de toda a vida é indispensável para que o efeito preventivo do flúor aconteça ${ }^{15}$. Por isso a grande importância da fluoretação das águas no âmbito coletivo da prevenção de cárie, pois não demanda intervenção profissional nem iniciativa da população, que, ao realizar um ato corriqueiro como beber água do abastecimento público, já está sendo beneficiada ${ }^{17}$.

Especialistas em saúde pública e a comunidade odontológica internacional consideram a fluoretação das águas uma medida efetiva no declínio da prevalência da doença cárie ${ }^{18}$. A água fluoretada também exerce efeito quando utilizada para o preparo de alimentos ${ }^{17}$.

Nos países do hemisfério sul, a doença cárie continua sendo um grande problema no âmbito da saúde pública ${ }^{19}$. Mesmo com a Lei Federal $n^{\circ} 6.050$ de 1974, que determina a obrigatoriedade da fluoretação dos municípios brasileiros com estações de tratamento de água, ainda existem diversas localidades sem acesso à água fluoretada. Segundo Araujo 20 a concentração de flúor no abastecimento da água em países tropicais como o Brasil deve ficar entre 0,7 e 1,0 ppm de flúor, devido ao clima, que influencia diretamente no consumo de água.

A saúde bucal, segundo Narvai ${ }^{14}$, é parte integrante e inseparável da saúde geral do indivíduo e está diretamente relacionada às condições de alimentação, moradia, trabalho, renda, transporte, lazer, acesso aos serviços de saúde e à informação, independentemente de qualquer comunidade que seja.

\section{Metodologia}

O presente estudo foi do tipo transversal, observacional, analítico. Os dados foram coletados durante os mutirões de saúde, atividades estas, decorrentes de uma atividade de extensão universitária interdisciplinar em saúde desenvolvida pela Faculdade de Odontologia da Universidade Federal do Rio Grande do Sul (UFRGS), em duas comunidades de descentes de escravos do estado do Rio Grande de Sul, Brasil. A primeira comunidade quilombola é rural, Costa da Lagoa, composta de 37 famílias, residentes no município de Capivari do Sul, que se situa a 73,4 quilômetros de Porto Alegre.

Através da figura 1, percebe-se que esta comunidade, vive próxima a Lagoa dos Barros, permitindo aos moradores fazer em residências seus poços artesianos de uma menor profundidade. 


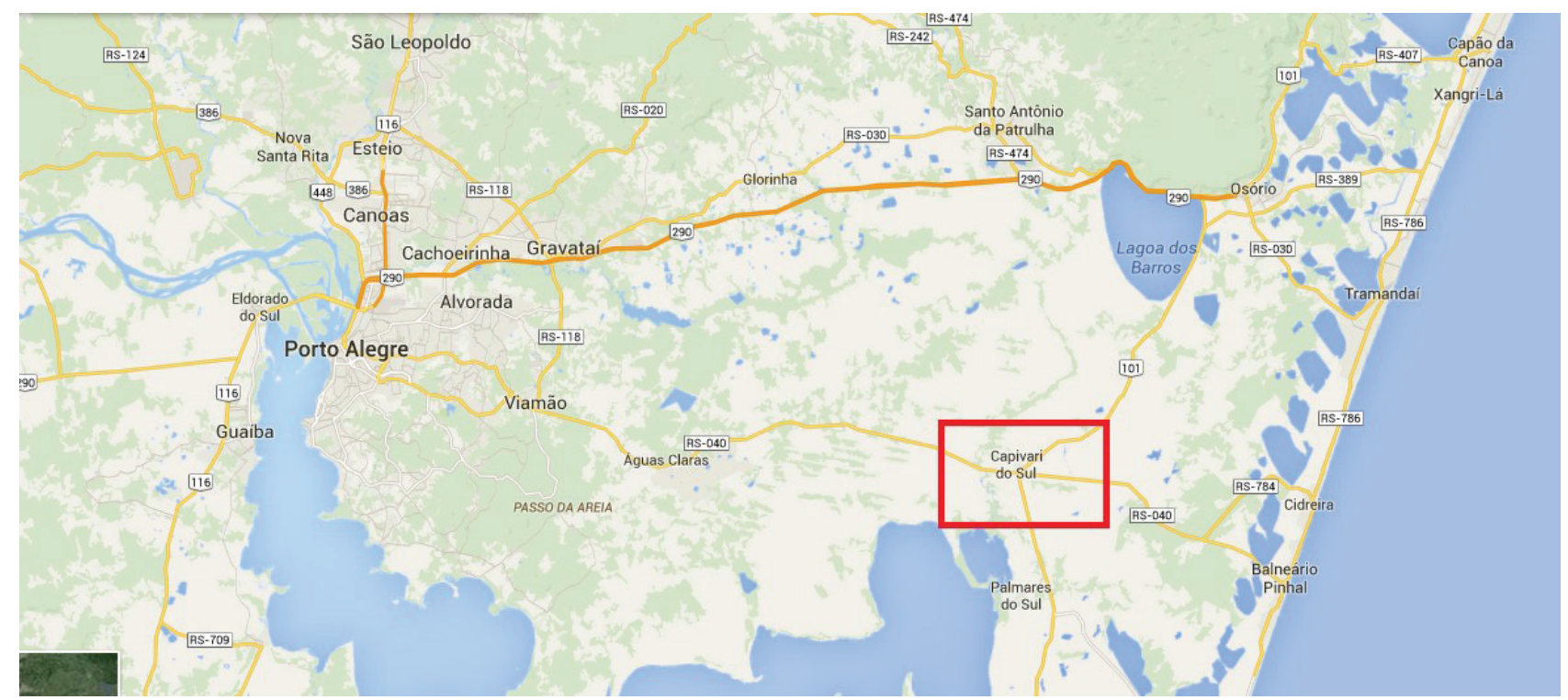

Figura 1 - Localização do Quilombo Costa da Lagoa destacado em vermelho, no município de Capivari do Sul, Rio Grande do Sul.

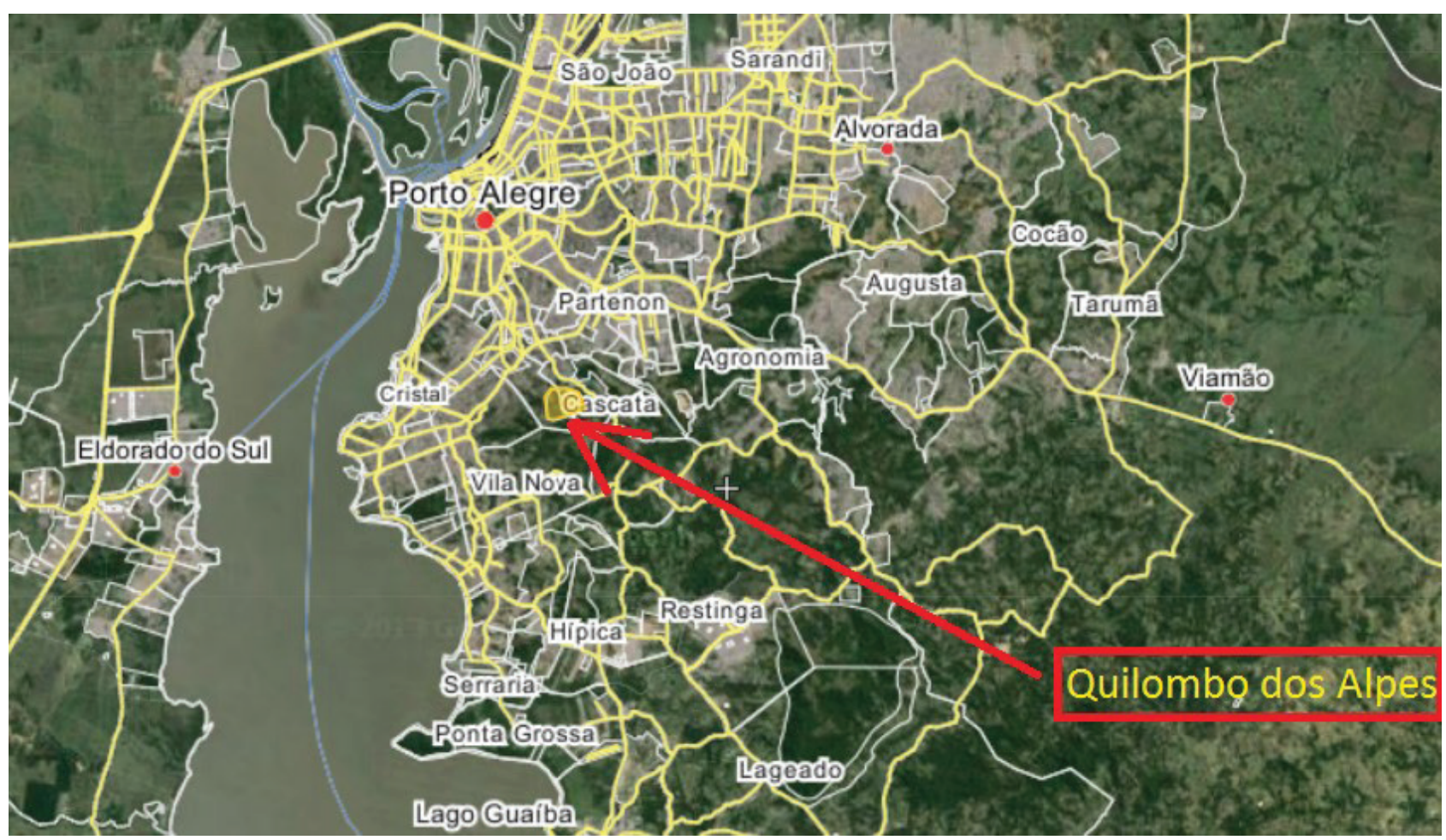

Figura 2 - Localização do Quilombo dos Alpes, destacado em amarelo, no município de Porto Alegre, Rio Grande do Sul. 
Verifica-se na figura 2, que a comunidade quilombola urbana dos Alpes, situa-se em Porto Alegre, no alto do Morro dos Alpes, região bem central do bairro Glória que se encontra no distrito sul da capital. Ela é composta de 70 famílias, que vivem em casas construídas de madeira e mista que são abastecidas pela água do Departamento Municipal de Água e Esgoto (DMAE).

Durante os mutirões de saúde, foi avaliada uma amostra de $25 \%$ da população de cada uma das comunidades, ou seja, dez famílias da comunidade rural (39 moradores) e dezessete da comunidade urbana (81 moradores), perfazendo um total de 120 quilombolas adultos avaliados.

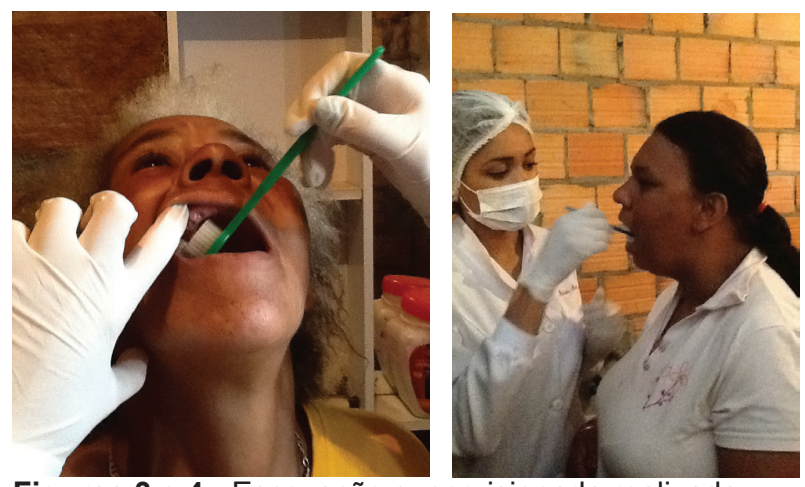

Figuras 3 e 4 - Escovação supervisionada realizada durante o mutirão de saúde na comunidade quilombola rural.

Para as condições de saúde bucal desses moradores, utilizou-se os critérios de presença ou ausência de placa visível e sangramento gengival, número de dentes cariados e perdidos. Estes exames bucais foram realizados por examinadores treinados mediante luz artificial nos ambientes mais claros das residências, sendo iniciados pela verificação da presença de placa visível, seguida da escovação supervisionada e observação de sangramento gengival. Após essa deplacagem, fez-se a secagem dos dentes com uma gaze e levantou-se o número de dentes cariados e perdidos restaurados (Figuras 5 e 6 ).
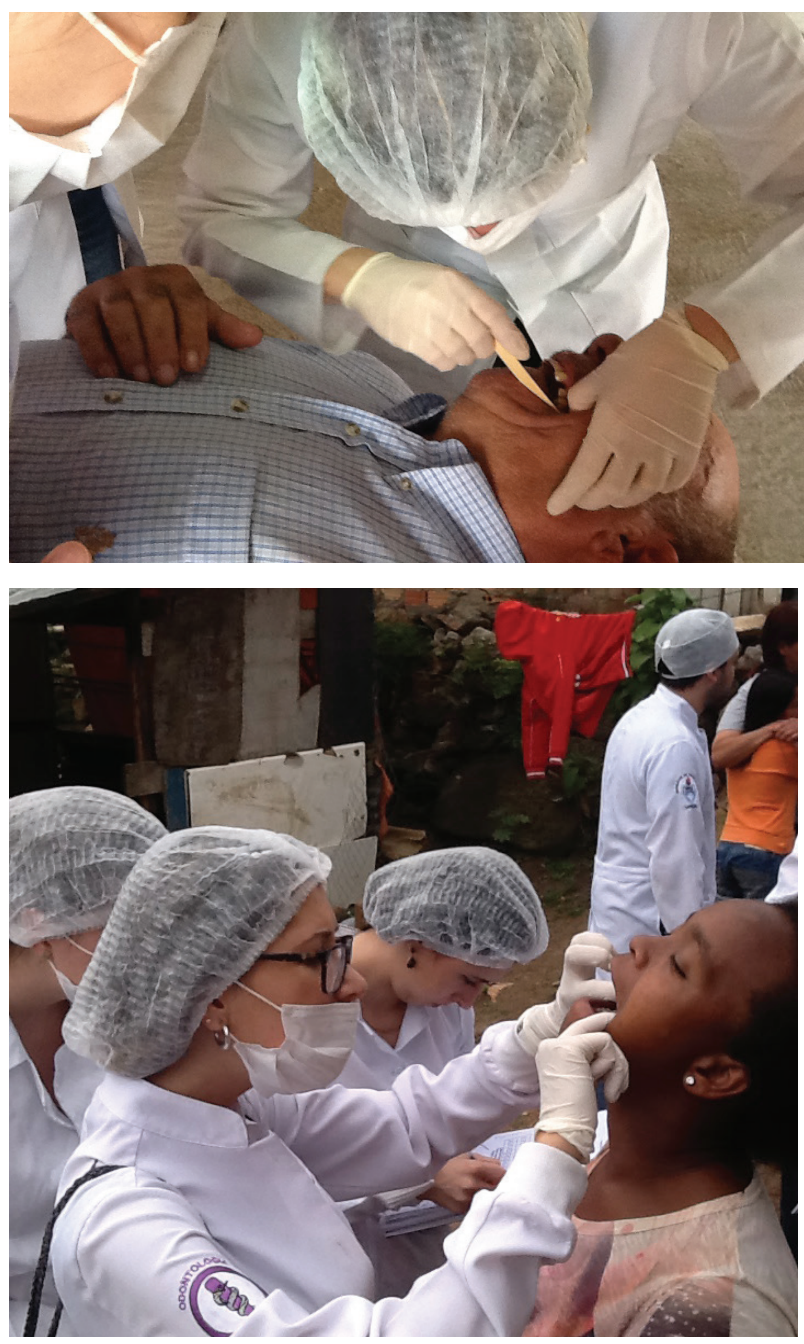

Figuras 5 e 6 - Comunidade quilombola em avaliação de suas condições de saúde bucal.

Os quilombolas também responderam a um questionário relacionado ao seu padrão alimentar, saúde geral e sua condição socioeconômica. Este foi realizado por acadêmicos de diferentes cursos de graduação da Universidade Federal do Rio Grande do Sul: odontologia, enfermagem, medicina, nutrição, veterinária, biologia, serviço social e antropologia, o que facilitou o diálogo entre a Extensão, o Ensino e a Pesquisa, tríade que norteia a estrutura universitária. As diferentes atividades comunitárias desenvolvidas confirmaram ainda mais a proposta de interdisciplinaridade junto a comunidades quilombolas (Figura 7). 


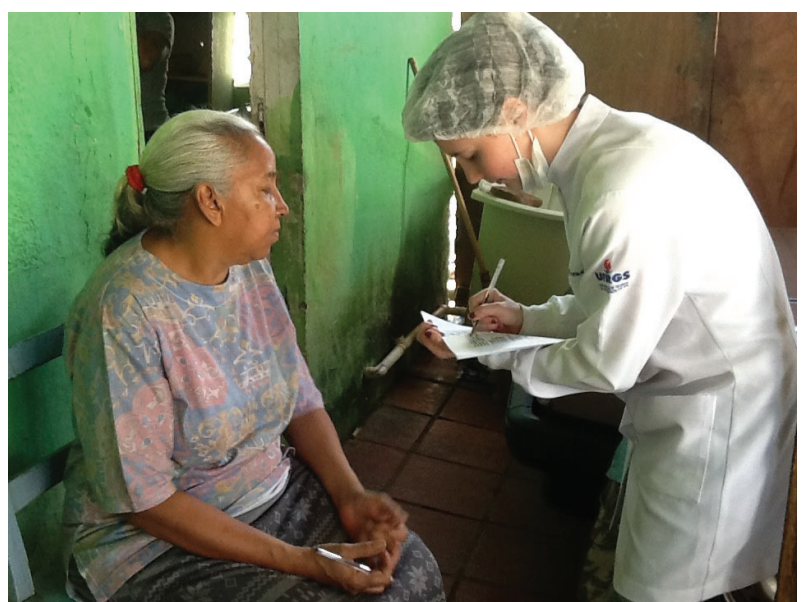

Figura 7 - Uma senhora da comunidade quilombola urbano respondendo ao questionário.

Paralelamente aos exames clínicos foram realizadas coletas das águas para medição do Flúor em quatro pontos básicos em residências da comunidade de Capivari do Sul e da fonte de abastecimento (visto que a comunidade não é abastecida por rede de água fluoretada). Estas medições foram realizadas pelo Centro de Ecologia da UFRGS. Para esta coleta todos responderam a um questionário específico sobre a água de consumo. A comunidade quilombola dos Alpes recebe abastecimento de água pelo DMAE, que possui uma concentração de flúor que pode variar de 0,6 a 0,9 mgF/L, de acordo com a temperatura. Portanto, não foi necessária a medição do Flúor.

Os dados coletados foram armazenados no programa Microsoft Excel 2010, sendo analisados quantitativamente, com tabelamento em percentual e apresentados em frequência relativa absoluta.

Os participantes da pesquisa assinaram um termo de consentimento livre esclarecido. Este foi aprovado pelo Comitê de Ética em Pesquisa da SMS de Porto Alegre sob o número 669, processo número: 001.032690.11.8, datado de 09/08/2011.

\section{Resultados}

Do total da amostra de 120 indivíduos, com idade média 39.6 anos de idade, $35.9 \%$ foram homens com uma média de idade de 39.8 anos, e $64.1 \%$ foram mulheres com idade média similar de 39.5 anos. Essa amostra foi divida para fins didáticos em adultos jovens (de 18 a 40 anos) e adultos maduros (de 41 a 60 anos), segundo Figueiredo et al em $2011^{21}$, sendo que a maior parcela se constitui de jovens, com a média de idade de 29 anos. A média de idade dos adultos maduros foi de 55.2 anos, conforme a Tabela 1.

Tabela 1 - Média de idade e percentual da população quilombola rural e urbana juntas

\begin{tabular}{ccccc}
\hline & Homens & Mulheres & $\begin{array}{c}\text { Adultos } \\
\text { Jovens }\end{array}$ & $\begin{array}{c}\text { Adultos } \\
\text { Maduros }\end{array}$ \\
\hline $\begin{array}{c}\text { Média de } \\
\text { Idade }\end{array}$ & 39.8 & 39.5 & 29.0 & 55.2 \\
$\begin{array}{c}\text { \% na } \\
\text { População }\end{array}$ & $35.9 \%$ & $64.1 \%$ & $57.6 \%$ & $42.4 \%$ \\
\hline
\end{tabular}

Com relação à comunidade quilombola de Capivari do Sul, foi observado que $70 \%$ desta população vivia com uma renda familiar que variava entre um e dois salários mínimos mensais. Com relação à escolaridade, $60 \%$ possuíam o $1^{\circ}$ grau incompleto. Quanto ao padrão alimentar, observou-se uma preferência por cereais, pães e raízes, seguidos por frutas e hortaliças. A maioria das famílias apresentou uma frequência alimentar de 3 a 4 refeições por dia. Quanto à saúde bucal, o edentulismo, configurado pela ausência total de dentes, estava presente em $13.4 \%$ dos adultos maduros. Mais da metade da população, apresentava pelo menos uma lesão de cárie, havendo uma média de dois dentes cariados por pessoa. $40 \%$ dos adultos jovens apresentavam lesões cariosas (Tabela 2). 
Tabela 2 - Edentulismo e cárie na população quilombola rural

\begin{tabular}{cccc}
\hline & $\begin{array}{c}\text { População } \\
\text { Total }\end{array}$ & $\begin{array}{c}\text { Adultos } \\
\text { Jovens }\end{array}$ & $\begin{array}{c}\text { Adultos } \\
\text { Maduros }\end{array}$ \\
\hline Edentulismo & $18 \%$ & $12,8 \%$ & $13.4 \%$ \\
$\begin{array}{c}\text { Média de dentes } \\
\text { perdidos }\end{array}$ & 15 & 13 & 14 \\
$\begin{array}{c}\text { Presença de } \\
\text { cárie }\end{array}$ & $50.3 \%$ & $43,9 \%$ & $45.1 \%$ \\
$\begin{array}{c}\text { Média de dentes } \\
\text { cariados }\end{array}$ & 2 & 2 & 2 \\
\hline
\end{tabular}

Quanto ao questionário das águas aplicado, todos os entrevistados sabiam de onde vinha a água consumida em suas casas, e acreditavam que a comunidade contava com um abastecimento de água seguro que satisfazia as necessidades domésticas tais como o consumo, a preparação de alimentos e a higiene pessoal. A maioria dos entrevistados acreditava que a água que tinham acesso era livre de bactérias capazes de originar enfermidades e de qualquer mineral ou substância orgânica que pudesse prejudicar a saúde e, portanto, não filtravam a água para consumo.

$\mathrm{Na}$ análise do flúor realizado no Centro de Ecologia da UFRGS, observou-se insignificante o limite de detecção de fluoreto ( $\mathrm{mgF} / \mathrm{L})$ nas águas coletadas da comunidade rural (Tabela 3).

Tabela 3 - Detecção de fluoreto ( $\mathrm{mgF} / \mathrm{L})$ nas águas coletadas da comunidade rural

\begin{tabular}{ccccc}
\hline \multicolumn{5}{c}{ RESULTADOS } \\
\hline $\begin{array}{c}\text { Medida } \\
\text { Fluoreto } \\
\text { mgF/L }\end{array}$ & LAGO & CASA 1 & CASA & CASA3 \\
& 0,12 & 0,14 & 0,10 & ND \\
\hline
\end{tabular}

LD =limite de detecção $=0,10$

Metodologia- Eletrodo de íon seletivo Referência: Standart Methods 21st.

Com relação à comunidade quilombola urbana dos Alpes, foi verificado que a renda mensal da maioria das famílias foi de até um salário mínimo mensal. No que diz respeito à escolaridade, $80 \%$ dos entrevistados possuíam o primeiro grau incompleto. Quanto ao padrão alimentar, a maioria afirmou se alimentar principalmente de legumes, carnes, ovos, leites e derivados, seguidos por açúcares e doces, óleos e gorduras. A maioria das famílias relatou se alimentar mais de quatro vezes ao dia. $\mathrm{Na}$ avaliação odontológica foi verificado que aproximadamente $5 \%$ dos adultos jovens apresentavam cáries e apresentavam muitos dentes restaurados. $18 \%$ da população apresentavam edentulismo, e também possuíam perda de mais de dez dentes (Tabela 4).

Tabela 4 - Edentulismo e cárie na população quilombola urbana

\begin{tabular}{cccc}
\hline & $\begin{array}{c}\text { População } \\
\text { Total }\end{array}$ & $\begin{array}{c}\text { Adultos } \\
\text { Jovens }\end{array}$ & Adultos \\
\hline Edentulismo & $18 \%$ & $9.2 \%$ & $12.8 \%$ \\
$\begin{array}{c}\text { Média de dentes } \\
\text { perdidos } \\
\text { Presença de }\end{array}$ & 15 & 7 & 13 \\
$\begin{array}{c}\text { cárie } \\
\text { Média de dentes } \\
\text { cariados }\end{array}$ & 2 & $4.9 \%$ & $41 \%$ \\
\hline
\end{tabular}

A população quilombola dos Alpes utilizava para consumo a água advinda do DMAE, que possuía uma concentração de flúor que varia de acordo com a temperatura. Segundo o relatório de análises de fluoreto disponibilizado pelo DMAE, o teor ideal de concentração do íon fluoreto na água de abastecimento público em Porto Alegre é de 0,8 ppm/F, sendo considerado dentro do padrão adequado, as análises que apresentarem concentração na faixa de 0,6 a $0,9 \mathrm{ppm} / \mathrm{F}$. Este intervalo foi adotado para todo Rio Grande do Sul a partir da Portaria $n^{\circ} 10 / 99$, da Secretaria da Saúde do Rio Grande do Sul que define os teores de concentração do íon fluoreto nas águas para consumo humano fornecidas pelo sistema público de abastecimento ${ }^{22}$. 


\section{Dıscussão}

Os resultados obtidos demonstraram uma grande prevalência de cárie em ambas as comunidades, porém houve um maior índice da doença na comunidade rural de Capivari do Sul. (Tabelas 2 e 4). Como consequência disso há também muitas perdas dentárias. Essa situação já caracteriza prejuízo à funcionalidade da dentição, uma vez que ela é preservada quando mantidos, ao menos, 20 dentes bem distribuídos em ambas às arcadas. Uma dentição funcional prejudicada implica distúrbios essencialmente na mastigação e na fala, afetando diretamente a qualidade de vida e a autoestima do indivíduo, pois se tratam de atividades ligadas ao prazer, ao suprimento de necessidades humanas e, ainda, à socialização na comunidade onde está inserido.

Por outro lado, acredita-se que o maior índice de cárie no quilombo rural de Capivari do Sul deve-se ao fato desta comunidade não ter acesso aos serviços públicos de atendimento odontológico e ter seus dentes tratados, e também, por ser desassistida pelos benefícios advindos da água de abastecimento público fluoretada. Pode-se atribuirissoàação protetora do flúor, às frequentes desmineralizações e remineralizações do esmalte dentário que ocorre diversas vezes durante a vida. O processo de desmineralização ocorre quando há uma queda no $\mathrm{pH}$ bucal $(\mathrm{pH}$ menor que $5,5)$. O flúor atua na fase da remineralização, formando fluoreto de cálcio que se precipita sobre o esmalte dentário tornando a superfície dentária mais resistente a desmineralização e, consequentemente, a cárie dentária. O consumo de água fluoretada permite que a população seja exposta frequentemente a pequenos níveis de flúor diariamente, constituindo-se em uma ação muito efetiva na prevenção da doença cárie. Sendo assim, o abastecimento de água fluoretada demonstra extremamente importante no âmbito coletivo.
Levando isto em consideração compreendese o fato de a comunidade de Capivari do Sul apresentar um maior índice de cárie quando comparada a comunidade dos Alpes, que possui acesso à água fluoretada.

Interessante ressaltar que com relação à dieta, o quilombo de Capivari do Sul (Costa da Lagoa) se diferencia do quilombo dos Alpes por plantar grande parte do que é consumido por eles, característica de populações que vivem na zona rural. Logo, não consumiam tantos alimentos industrializados, como a comunidade urbana dos quilombos dos Alpes, que tem como tradição do cultivo apenas de ervas medicinais e temperos.

Mas independentemente do fato supracitado, a comunidade quilombola urbana tem mais facilidade de acesso aos serviços odontológicos do município. Existe uma Unidade Básica de Saúde (UBS) próxima ao quilombo dos Alpes com cirurgiões dentistas e estagiários de universidades que prestavam atendimento seja ele de qualquer natureza, perfil este, completamente diferente da comunidade quilombola rural, que não tem facilidade de acesso ao serviço odontológico, mas que demonstraram ainda precariedade na resolução dos problemas desta população. Independente de acesso ou não, o padrão de serviços em saúde bucal para a população quilombola residente na zona rural ou urbana foi à extração dentária em massa como solução mais prática e econômica para a resolução de seus problemas. Isso pode ser confirmado no presente estudo, onde edentulismo se deu em percentuais idênticos na população total de ambos os quilombos. A proposta de se estudar as condições bucais destes grupos é adequada à necessidade de fundamentar ações concretas de intervenção que visem melhorar os padrões de saúde bucal desta população.

Com relação à maneira que viviam suas práticas e costumes, pôde-se constatar que 
ambas as comunidades ainda conservavam muitos traços de suas tradições. No quilombo dos Alpes, por exemplo, a religião predominante entre os quilombolas era o candomblé, credo trazido pelos negros africanos ao Brasil. A comunidade valorizava muito a religião, demonstrando sua fé através de oferendas dedicadas aos orixás e realizando festas em homenagem aos mesmos. No quilombo de Capivari, ainda que menos expressiva, a religião africana também era a eleita pela maioria das famílias quilombolas. No que diz respeito às suas lutas por terra, houve uma similaridade entre as falas das duas representantes dos quilombos. Ambas relataram muitos conflitos até conseguirem ter suas terras reconhecidas. O quilombo Costa da Lagoa foi reconhecido e recebeu suas terras recentemente. O quilombo dos Alpes, apesar de reconhecido formalmente desde 2005, ainda recebe investidas de imobiliárias que ameaçam a sua estabilidade territorial.

Ressalta-se aqui que a partir do Decreto 4887/03, publicado no Diário Oficial da União ${ }^{23}$ ficou transferida do Ministério da Cultura para o INCRA a competência para a delimitação das terras dos remanescentes das comunidades dos quilombos, bem como a determinação de suas demarcações e titulações.

Interessante destacar que em 12 de março de 2004, o Governo Federal lançou o Programa Brasil Quilombola (PBQ) como uma política de Estado para as áreas remanescentes de quilombos. Este programa reúne diversas ações inseridas nos diversos órgãos governamentais, e possui como meta a garantia do acesso a terra através da regularização fundiária, ações de saúde e educação, construção de moradias, eletrificação, recuperação ambiental, incentivo ao desenvolvimento local (fruto de parcerias entre SEPPIR, Eletrobrás, Petrobrás, Caixa Econômica Federal, Fundação Universidade de Brasília e Ministério do Desenvolvimento Social e Combate à Fome), pleno atendimento das famílias quilombolas pelos programas sociais, como o Bolsa Família, e medidas de preservação e promoção das manifestações culturais quilombolas. Dentre todas essas ações citadas, a política de regularização é atribuição do INCRA ${ }^{24}$.

Apesar do $\mathrm{PBQ}$ em pleno vigor há 10 anos, observou-se que as duas comunidades apresentavam um baixo nível socioeconômico. Mais de $60 \%$ dos quilombolas avaliados de ambas as comunidades possuíam até $01^{\circ}$ grau incompleto e, a maioria das famílias tinha como renda mensal de até um salário mínimo sendo que em sua maioria eram compostas por 3 a 5 moradores por residência vivendo em situação precária, o que caracteriza estas populações estar abaixo da linha da pobreza.

Finalizando, apesar da progressiva democratização do acesso à saúde para a população quilombola, as condições de pobreza extrema prevaleceram tanto para as comunidades que viviam nos centros urbanos como no meio rural e, conforme afirmado anteriormente isto contribuiu substancialmente para a alta prevalência de doenças bucais encontradas. Fica um indicativo de que é necessário adaptar as políticas públicas de saúde bucal às características de cada quilombo, se for um quilombola rural, o acesso seria diferenciado dos residentes em zona urbana. Também é importante que a formação do profissional de saúde esteja mais adaptada para atender à realidade vivida pela população quilombola brasileira através das reformas curriculares que contemplem os princípios do cuidado humanizado, integral e descentralizado a esta população ${ }^{25,26}$.

Ações interdisciplinares em saúde, semeIhante às adotadas no desenvolvimento desta pesquisa, para promover saúde através do atendimento, a uma população quilombola desassistida principalmente do meio rural, devem ser adotadas pelas universidades de forma que haja uma contribuição para a 
sociedade e concomitantemente prepare o acadêmico para uma formação profissional inserida na realidade do país.

\section{Conclusões}

Através deste levantamento foi possível identificar um perfil carente de saúde bucal e de nível socioeconômico das populações quilombolas rural e urbana: baixa remuneração e escolaridade, apresentando altos índices de placa visível, sangramento gengival, cárie e perdas dentárias.

A comunidade quilombola rural apresentou um percentual maior de dentes cariados e perdas dentárias sugestivo de ser uma população desassistida pelos benefícios advindos da água de abastecimento público fluoretada e assistência odontológica preventiva-educativa.

\section{REFERÊNCIAS}

1. Freitas D. O Escravismo Brasileiro. 3. ed. Porto Alegre: Mercado Aberto, 1991.

2. Anjos RSA, Cipriano A. Quilombola: Tradições e Cultura da Resistência. São Paulo: Aori Comunicações; 2006.

3. Ramires I, Buzalaf MA. A fluoretação da água de abastecimento público e seus benefícios no controle da cárie dentária - cinquenta anos no Brasil. Ciênc Saúde Colet. 2007 jan-mai; 12(4): 1057- 1065.

4. Muller CB. Direitos Étnicos e Territorialização: dimensões da territorialidade em uma comunidade negra gaúcha. Porto Alegre: UFRGS; 2011

5. Maestre MJ. O escravo gaúcho. Resistencia e Trabalho. São Paulo: Brasiliense; 1984.

6. Rubert R. Comunidades Negras Rurais do RS [Um levantamento socioantropológico preliminar]. Porto Alegre: Secretaria de Agricultura e abastecimento do Estado do Rio Grande do Sul/RS RURAL; Instituto Interamericano de Cooperação para a Agricultura - IICA; 2005.
7. Nascimento A. O Quilombismo: documentos de uma militância pan-africanista. Petrópolis: Vozes; 1980.

8. Linhares LF. Comunidade negra rural: um velho tema, uma nova discussão. Rev Palmares em Ação. 2002; 1(1).

9. Gomes F. Palmares: Escravidão e Liberdade no Atlântico Sul. São Paulo: Contexto; 2005.

10. Neto CS. Comunidades Negras Tradicionais do Paraná - Relato do trabalho realizado pelo Grupo de Trabalho Clóvis Moura / Secretaria de Cultura do Estado do Paraná. Curitiba; 2006.

11. Brasília. Comissão Nacional de Desenvolvimento Sustentável dos Povos e Comunidades Tradicionais. Política Nacional de Desenvolvimento Sustentável de Povos e Comunidades Tradicionais. Brasília; set. 2006 [acesso em 27 março 2016]. Disponível em: http://www.mds.gov.br/acesso-a-informacaoorgaoscolegiados/orgaos-em-destaque/cnpct.

12. São Paulo. Comissão Pró-índio de São Paulo, 2011. [acesso em 28 abr. 2016] Disponível em: http://www.cpisp.org.br/terras/.

13. Santos M., Santos R. Fluoretação das Águas de Abastecimento Público no Combate à Cárie Dentária. Rev Bras Ciênc Saúde. 2011;15(1):75-80.

14. Narvai P. Cárie dentária e flúor: uma relação do século XX. Ciênc Saúde Colet. 2000; 5(2):381392.

15. Cury JA. Flúor: dos 8 ao 80?. In: Bottino MA, Feller C. Atualização na clínica odontológica. São Paulo; Artes Médicas, 1992. p.375-82.

16. Featherstone JD. Prevention and reversal of dental caries: role of low level fluoride. Community Dent Oral Epidemiol. 1999; 27(1): 3-40.

17. Frias AC, Narvai PC, Araujo ME, Zilobovicius C, Antunes JLF. Custo da fluoretação das águas de abastecimento público, estudo de caso Município de São Paulo. Cad Saúde Públic. 2006 jun; 22(6):1237-1246.

18. Narvai $P C$, Frazão $P$, et al. Cárie dentária no Brasil: declínio, polarização, iniquidade e exclusão social. Rev Pan Sal Púb. 2006 jun; 19(6): 12- 29.

19. Ribeiro AG, Oliveira AF, Rosenblatt A. Cárie precoce na infância: prevalência e fatores 
de risco em pré-escolares, aos 48 meses, na cidade de João Pessoa, Paraíba, Brasil. Cad. Saúde Pública. 2005; 21(6):1695-1700.

20. Araujo MT, Campos EJ, Rodrigues CS, Serravale LS, Lima MJ, Araujo DB. Ação do fluoreto de dentifrícios sobre o esmalte dentário. Rev Cienc. Méd Biol. 2002;1(1):16-32.

21. Figueiredo, MC ; Silva, K V C L; Faneze, J L; Gass, E L. Saúde bucal de moradores de um bairro pobre de Xangri-Lá, RS, Brasil. ConScientiae Saúde. 2011;10(2):177-183.

22. Porto Alegre. Portaria . $^{\circ} 10 / 99$ de 11 de agosto de 1999. Define teores de concentração do íon fluoreto nas águas para consumo humano fornecidas por Sistemas Públicos de Abastecimento. 1999 agost. 22 [acesso em 10 jun 2016 ]. Disponível em: http://www. planalto.gov.br/ccivil_03/_ato2007-2010/2007/ lei/l11445.htm.

23. Brasília. Decreto $n^{\circ} \mathbf{4 . 8 8 7}$ de 20 de novembro de 2003. Regulamenta o procedimento para identificação, reconhecimento, delimitação, demarcação e titulação das terras ocupadas por remanescentes das comunidades dos quilombos de que trata o art. 68 do Ato das Disposições Constitucionais Transitórias. Diário Oficial da União. 2003 nov. 20 [acesso em
10 jun 2016]. Disponível em: https://quilombos. wordpress.com/legislacao/.

24. Brasília. Ministério do Desenvolvimento Agrário [BR] Quilombolas, Programa Brasil Quilombola (PBQ),2004 [acesso em 10 jun 2016]. Disponível em: http://www.incra.gov.br/ quilombolas.

25. Figueiredo, MC et al - Descrição do padrão alimentar e da saúde bucal de crianças do sul do Brasil. RFO, Passo Fundo.2014 Set./ Dez;19(3):329-336,

26. Figueiredo, M C; Garcia, M; Barone, DAC Oliveira, R; Lurmmerz, G. Gamificação em saúde bucal: experiência com escolares de zona rural. Rev da ABENO. 2015;v.15(3):98-108.

Agradecimentos

Os autores agradecem as comunidades quilombolas Costa da Lagoa e dos Alpes por permitirem o desenvolvimento da referida pesquisa em seus territórios e, a pró-reitoria de Extensão da Universidade Federal do Rio Grande do Sul por todo apoio dado para a execução deste trabalho.

Submetido em: 11-7-2016

Aceito em: 22-8-2016 